\title{
The Effect of Service Quality on T-Cash Customer Satisfaction using System Dynamics Framework
}

\author{
Dhyna Octabriyantiningtyas ${ }^{1)^{*}}$, Erma Suryani ${ }^{2)}$ \\ ${ }^{1) 2)}$ Institut Teknologi Sepuluh Nopember, Indonesia \\ Jl. Raya ITS Keputih, Sukolilo, Surabaya \\ 1)dhyna.octabriyan@gmail.com, ${ }^{2}$ erma.suryani@gmail.com
}

Article history:

Received 3 February 2019

Revised 2 April 2019

Accepted 5 April 2019

Available online 28 April 2019

Keywords:

Customer Satisfaction

Service Quality

System Dynamics

T-Cash

\begin{abstract}
Background: Every year, the number of T-Cash users is increasing significantly. However, the increase is not in sync with the number of T-Cash transactions. In this year, it was noted that active T-Cash users were only 35\%. Some clinical studies have established an assessment of the quality of services, there are several dimensions assessed according to the topic of research. The dimensions of service quality used in this study are dimensions of efficiency, reliability, responsiveness, privacy, and security.

Objective: This study aims to build general models and simulations in increasing customer satisfaction with the quality of T-Cash services and produce the best scenarios that can be used by policymakers in increasing customer satisfaction.

Methods: System dynamics framework is utilized for the development of the model and scenarios. Because by using a system dynamics framework can predict service quality sometime in the future so that it can produce policies for the company.

Results: The simulation results are considered valid because they produce E1 values of $3 \%$ (E1 valid when $\mathrm{E} 1 \leq 5 \%)$ and $\mathrm{E} 2$ of $7 \%$ (E2 valid when $\mathrm{E} 2 \leq 30 \%)$. E1 is mean comparison and E2 is error variance. Based on these 2 scenarios, a policy can be taken that scenario 1 significantly increases customer satisfaction compared to scenario 2 . Conclusion: Based on the simulation that has been done, it can be concluded that the dimensions of responsiveness, privacy, reliability, security, and efficiency have an effect on improving service quality. On the scenario 1 , it can be concluded that with the addition of the user friendliness dimension, the service quality will experience a significant increase over the next 5 years.
\end{abstract}

\section{INTRODUCTION}

The development of information technology in the present continues to progress, so that makes modern society so dependent and feels increasingly difficult to separate from technology. While with the existence of these technologies, such as there are no more restrictions in the environment. Many things can be known, done, and facilitated by the presence of technology. So that with the development of technology continuously is expected to have a positive impact on the development and progress of the nation. As in the world of banking, technological developments have a big impact because the presence of new technologies that continue to emerge can make it easier to make transactions. Innovations in the banking world continue to be born and developed through modern technology to provide the best service to consumers. One important activity in the economic cycle is transaction activity, where the activity involves payment tools. Payment tools are an important part of the banking world and are experiencing rapid changes following technological developments.

Non-cash transactions can also increase business productivity because it allows the businessman to track all transactions more quickly. For consumers, the benefits obtained when conducting transactions using the noncash system are providing convenience for 24-hour transactions with convenience and lower costs. On the other hand, for the government, non-cash transactions will encourage economic efficiency. Cost savings will start with printing costs and also the cost of distributing money, cash handling, to administrative management. Some cellular operators in Indonesia also participated in the success of the National Non-Cash Movement program by issuing e-money products, one of which was PT. Telekomunikasi Seluler (Telkomsel).

Every year T-Cash users increase significantly, but the increase is not accompanied by an increase in transactions made using T-Cash. Based on the results of observations at PT. Telkomsel recorded that only TCash active users were only $35 \%$. The majority of T-Cash users experience the intensity of using T-Cash as an electronic payment service. Users who initially use 2 times a month can go down to once a month or even do no

\footnotetext{
Corresponding author
} 
transactions at all. In addition to top up, which is usually done once a month, it can go down to once every two months or not even top up at all since the first time it was registered. With these things it can be illustrated that there is a decrease in customer loyalty towards T-Cash products from Telkomsel. For this reason, it is necessary to explore customer satisfaction with the T-Cash application, so that it can improve the quality of products according to the customer's wishes. And it is necessary to make simulations to increase customer satisfaction that affects the profit of Telkomsel.

S. Khan and Mahapatra [1] stated that the main factors in service quality are reliability, accessibility, userfriendliness, privacy/security, efficiency, responsiveness, and fulfillment. Behjati [2] created a conceptual framework that will facilitate the development of quality electronic services and measure validity and reliability for customer loyalty and satisfaction. Based on the findings, there are 9 independent dimensions that influence customer loyalty and satisfaction, namely trustworthiness, reliability, ease of use, security, personalization, responsiveness, accessibility/convenience, aesthetic and utilitarian. But this research only uses the quality of electronic services in general. According to L. Zhao et al [3], there are 5 dimensions that can explore the relationship between service quality and customer satisfaction, namely efficiency, reliability, responsiveness, fulfillment and privacy. Based on previous research, the author will combine several dimensions to determine the service quality of T-Cash. In this study, the author uses the dimensions of responsiveness, privacy, security, reliability, and efficiency. Previously, there had never been a model for T-Cash customer satisfaction based on the quality of T-Cash services. Therefore, the author makes the model for consideration companies to make policies in order to maintain the satisfaction and loyalty of T-Cash customers.

The purpose of this research is to build a general model of simulation systems that aims to maintain and improve T-Cash customer satisfaction through service quality and produce the best scenario that can be used by companies in maintaining and increasing customer satisfaction through the service quality of T-Cash.

This paper is organized as follows : section 2 is literature review; section 3 is method; section 4 is the results; section 5 is discussion; and the last section is conclusions.

\section{LITERATURE REVIEW}

Some researchers define customer satisfaction to assess customer responses to a product. According to Kotler [4], mentions satisfaction is a person's happy feeling or result of disappointment over the comparison of perceptions of product performance (results) in relationships or expectations. While according to Y. Kuo et. al [5], customer satisfaction is a function of customer trust where he is treated fairly. Customer satisfaction will be felt from the return of customers to buy or use company products and services. Customers whose satisfaction will positively affect customer retention and secure future income [6]. Satisfied customers will bring strong loyalty with a focus on the company [7]. Customer satisfaction results in repeated purchases, loyalty, positive words and high profitability [8]. The main indicators of customer satisfaction are trust, commitment, communication, service quality, service satisfaction and service handling [9].

Yang and Fang [10] identified that there are 5 dimensions of the quality of online services including reliability, responsiveness, competence, access, and security, where the five dimensions are used to evaluate service quality and customer satisfaction. F. Hamed et al [11] examined the relationship between online service quality and customer satisfaction. According to qualitative analysis data, the privacy dimension is the most noticed dimension because it is viewed from the point of view of a service's security and this dimension has a significant impact on service quality and customer satisfaction. Reliability and responsiveness are the next important dimensions and have a significant impact on trust. According to Zeithaml et al [12], customer loyalty is described as a natural consequence of service quality. Customer loyalty is a behavioral intention that follows a transaction related to perceived quality, service experience, and level of satisfaction [13]. The effects of service quality on certain behavioral intentions have been studied in several studies such as the willingness of customers to recommend companies, willingness to pay premium prices to companies and repeated buyers' intentions [2].

\section{METHODS}

This research is divided into 7 stages, consist of: identification of problem, literature study, data collection, system dynamics framework, verification and validation, scenario, and results of analysis [14].

\section{A. Identification of Problem}

At this stage, data and information collection are needed by conducting surveys and observations. Identifying problems were done by collecting data on the number of active and passive T-cash users recorded at PT. Telkomsel. And then, doing an observation on the user that causes decrease of transaction.

\section{B. Literature Study}

The next step is to look for literature studies related to the topic raised. The purpose of this stage is the author understands the methods that will be used in the preparation of research. The author studies and understands the 
increase in customer satisfaction through service quality and modeling using a system dynamics framework. Literature comes from e-books, journals, the internet, and other sources.

\section{Data Collection}

The third stage is data collection. At this stage, the authors collect data that is more detailed and closely related to the problems that have been identified previously. The data and information collected will then be poured into a system dynamics model. The technique used in data collection is in distributing questionnaire to T-Cash users. The author distributing 30 questionnaire to T-Cash users in Surabaya. In addition, the author also took data at PT. Telkomsel for data in previous years.

The questionnaire uses a Likert scale with a scale of "strongly disagree (1), disagree (2), no choice (3), agree (4), strongly agree (5)". Because service quality and satisfaction are defined as levels, not variables, so that they are compatible with the scale models of the modified 1, 2, 3, 4 and 5 questionnaires to the satisfaction levels of $0,25,50,70$ and 100 respectively. For example, if the value is average for the privacy value of 3.82 , it will be converted to a value of 64 which is defined as the privacy dimension on T-Cash "quite satisfactory".

\section{System Dynamics Framework}

System dynamics is defined as a field to understand how things change with time [15]. System dynamics is methods that can describe processes, behavior, and complexity in the system [16]. This system dynamics methodology has been and is being developed since it was first introduced by Jay W. Forester in the 1950s as a complex problem solving method that arises due to causal dependence of various variables in the system. Dynamics model is an experimental approach method that underlies the realities that exist in a system to observe the behavior of the system [17]. The purpose of a system dynamics methodology based on a cause and effect philosophy is to get a deep understanding of how a system works. The stages in the dynamic system approach are: Problem identification, system conceptualization, formulation, simulation, policy formulation and evaluation, and the last is implementation.

1) Causal Loop Diagram (CLD)

Data that has been collected is then identified into variables. Then the data is arranged in accordance with the interaction pattern in the form of causal loop diagrams. A causal loop diagram is a form of the system dynamics model that presents the structure of the feedback diagram (cause and effect). This diagram shows the direction of changes in variables and polarity. Flow polarity as stated above is divided into positive and negative [18].

2) Stock and Flow Diagram (Base Model)

Causal loop Diagrams that have been formed can be arranged again into more detailed parts, namely by making a flow diagram (stock and flow diagram or base model). Flow diagrams represent the relationships between variables that have been made in a causal diagram more clearly, using various symbols for various variables involved [17]. In stock and flow diagrams pay attention to the influence of time on the interrelationship between variables, so that each variable is able to show the accumulated results for variable levels, and variables that show the rate of system activity each time which is the rate. Data analysis is based on monthly data starting from 2007 - 2018. Stock and Flow Diagram of service quality describes the quality of service behavior that will affect customer satisfaction. Measurement of service quality is based on the dimensions of responsiveness, privacy, security, reliability, and efficiency.

\section{E. Verification and Validation}

The results of the flow diagram model that has been made will then be carried out the Verification and Validation process. Verification is the process of checking the model whether there has been no error. Verification is done by examining the formulations that have been made according to the relationship of variables with other variables and checking the unit of variables in the model. If there is no error in the model, the model has been verified. The Validation process is then carried out to ascertain whether the model matches the actual system conditions. The Validation process is carried out in two ways, namely model validation with statistic Average Comparison Test (mean comparison) or with model validation with a Comparison Test for Appendix Variation (\% error variance) [19].

\section{a. Mean Comparison}

$$
E 1=\left|\frac{\bar{S} \quad \bar{A}}{\bar{A}}\right|
$$

\footnotetext{
Information:

$E 1$ = Mean Comparison (\% error variance)

$\bar{S}=$ Average Value of Simulation Results

$\bar{A}=$ Data Average Value

Model is considered valid if $\mathrm{E} 1 \leq 5 \%$
} 
Information :

$E 2=\%$ error variance

$\mathrm{SS}=$ Standard Deviation Model

$\mathrm{Sa}=$ Standard Data Deviation

Model is considered valid if E2 $\leq 30 \%$

\section{F. Scenario}

In accordance with the objectives of the study, the model that has been built will be made a scenario to increase customer satisfaction. At this stage a policy simulation will be carried out to determine the behavior that will be generated, this simulation is carried out by comparing several policies to be taken and ensuring which policies have the best scenario.

\section{G. Results of Analysis}

In the final process, the author documents the results of the research which results in an affirmation of a policy that can be used by the company. Reports on research results written by the author follow the specified journal format.

\section{RESUlTS}

Data collection was done through the distribution of the questionnaire to T-Cash users that later processed and grouped based on service quality dimension variables. Then the data is modeled and simulated according to the purpose of this study.

\section{A. Causal Loop Diagram (CLD)}

Causal loop diagram is arranged based on component variables that have been identified. Causal loop diagram is a disclosure about the occurrence of a causal relationship into an image, where the image displays interrelated arrows forming a causal diagram. Negative and positive signs on causal loop diagrams illustrate the types of consequences by causes. If the relationship is in the direction of the arrow is positive $(+)$, but conversely, if the relationship is in the opposite direction, then the arrow is negative.

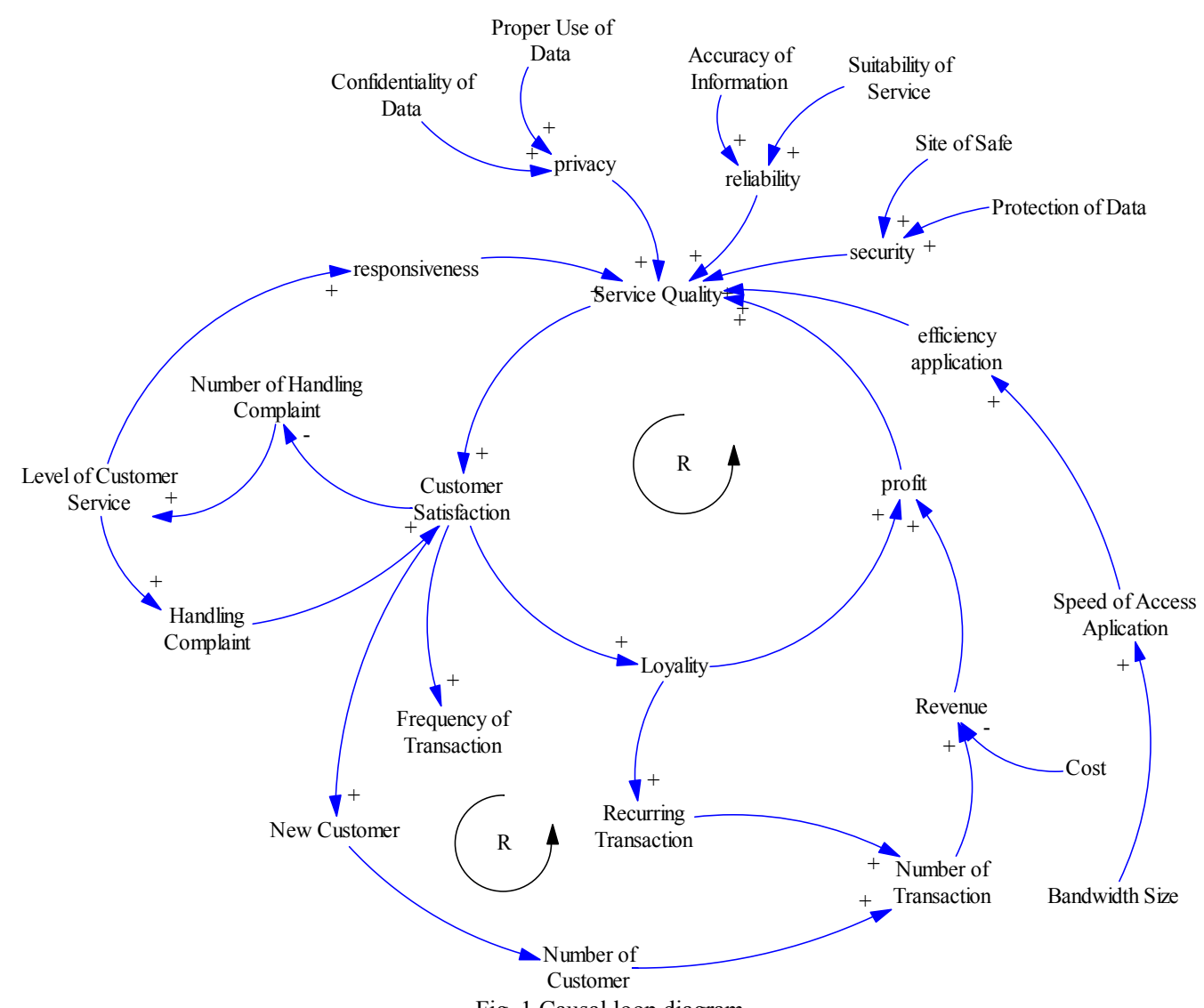

Fig. 1 Causal loop diagram 
The cause and effect diagram is made by linking the relationship of a variable with other variables. Thus it can be understood, the relevance and the extent of its influence. All variables that influence the problem are involved in the model. Increased service quality is influenced by responsiveness, privacy, reliability, security, and efficiency. Customer satisfaction affects number of handling complaint, frequency of transaction, new customer and loyality. Customer satisfaction can increase because it is influenced by service quality and handling complaint. Loyality affects recurring transactions and profits. Loyality can increase because it is influenced by customer satisfaction. From the conceptualization of the model through causal loop diagram on Fig. 1, it can be seen that the main purpose of modeling is to determine the behavior of T-Cash service quality that will affect customer satisfaction and customer loyalty.

\section{B. Base Model (Stock and Flow Diagram)}

Stock and flow diagram of service quality describes the service quality of T-Cash that affect customer satisfaction. Data initials at service quality level based on data taken from questionnaires distributed to T-Cash users. Measurement of service quality is based on the dimensions of responsiveness, privacy, reliability, security, and efficiency. Increased service quality is influenced by responsiveness, privacy, reliability, security, and efficiency. The time of data analysis is every month of the year and the length of the simulation is carried out for 12 years (2007-2018). Service quality stock and flow diagrams is shown in Fig. 2.

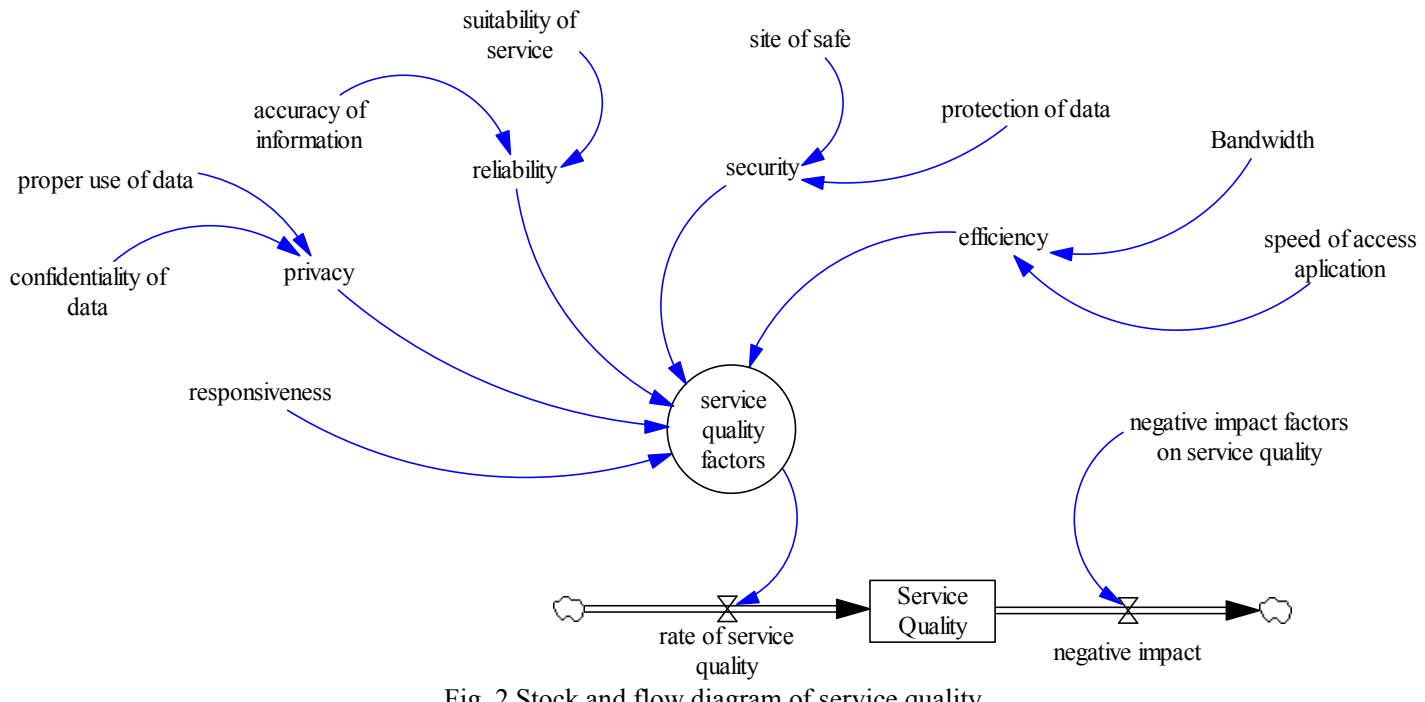

Fig. 2 Stock and flow diagram of service quality

Fig. 3 shows a graph of service quality T-Cash at Telkomsel. The service quality value scales $0-100$ from the average value dimension of service quality. The growth of service quality values is very volatile up and down. This shows that service quality T-Cash must be quickly overcome so that customers do not feel that service quality from T-Cash is bad. Because it affects customer satisfaction. Therefore, serious handling is needed to find out which dimensions have the most significant influence on the increase and decrease in service quality.

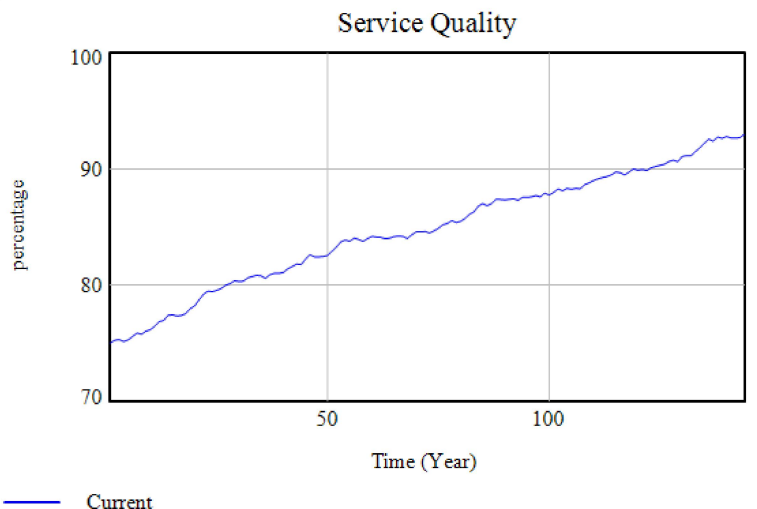

Fig. 3 Base model simulation result 
TABLE 1.

VALIDATION

\begin{tabular}{|c|c|c|}
\hline Year & Population Data & Population Model \\
\hline \multirow[t]{12}{*}{2007} & 75,2 & 75,0 \\
\hline & 75,2 & 75,2 \\
\hline & 75,2 & 75,3 \\
\hline & 74,8 & 75,1 \\
\hline & 75,6 & 75,3 \\
\hline & 76,3 & 75,6 \\
\hline & 75,3 & 75,8 \\
\hline & 75,9 & 75,7 \\
\hline & 75,3 & 76,0 \\
\hline & 75,8 & 76,2 \\
\hline & 75,9 & 76,5 \\
\hline & 76,0 & 76,9 \\
\hline etc & 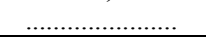 & 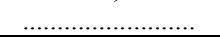 \\
\hline \multirow[t]{12}{*}{2018} & 89,9 & 91,5 \\
\hline & 90,4 & 91,9 \\
\hline & 91,0 & 92,2 \\
\hline & 91,6 & 92,6 \\
\hline & 91,3 & 92,4 \\
\hline & 91,9 & 92,8 \\
\hline & 91,7 & 92,7 \\
\hline & 92,0 & 92,8 \\
\hline & 91,8 & 92,7 \\
\hline & 91,8 & 92,7 \\
\hline & 91,8 & 92,7 \\
\hline & 92,3 & 93,0 \\
\hline AVERAGE & 82,4 & 84,8 \\
\hline STDEV & 4,6 & 5,0 \\
\hline E1 & & $3 \%$ \\
\hline E2 & & $7 \%$ \\
\hline
\end{tabular}

\section{Verification and Validation}

Conceptual model validation is the process of determining whether the theories and assumptions underlying the conceptual model are correct and reasonable for the proposed objectives of the model. Validation to ascertain whether the model matches the actual system conditions.

This Validation process is carried out in two ways, namely model validation with mean comparison statistics (1) or with model validation with error variance (2). Based on the average comparison test in the table above shows that the value of $\mathrm{E} 1$ is $3 \%$, then the model is considered valid because the value of $\mathrm{E} 1 \leq 5 \%$. Based on the comparison test of the amplitude variations in the previous table, it shows that the E2 value is $7 \%$, then the model is considered valid because the value of E2 is $\leq 30$. The model that has been made is considered valid because the graph shows that the data population and model population have intersected data, the graph can be seen in Fig. 4.

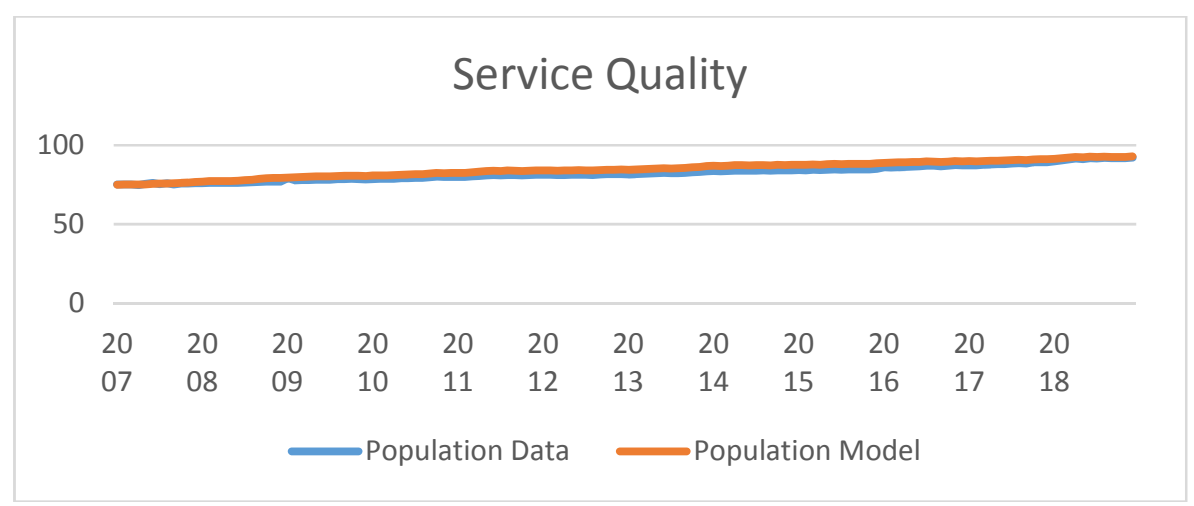

Fig. 4 Comparison of data population and data model

\section{Scenario}

Scenario development is made if the basic model previously made is valid. In this section, we will show how the system structure of the basic model can be changed by using some feedback loops by adding new parameters and changing the structure or called a structured scenario. And how the model parameters can be changed to see the impact of other variables of the system or commonly called parameter scenarios. Scenario development is a method of prognosis or forecasting where the results of the development of the scenario are used to develop various alternative possibilities in the future. 
Based on the existing model Fig. 2 that has been developed, the model can be used to design scenarios to obtain anticipatory policies that are effective against a variety of possibilities that can occur in the future. The draft scenario includes: 1) Scenario 1 concerning adding a new dimension to service quality, namely user friendliness, 2) Scenario 2 is the addition of infrastructure dimensions.

Scenario simulations are conducted to forecast the next 5 years, because usually changes in policy are based on changes in position that occur every 5 years, from 2019 until 2023.

\section{1) Scenario 1 Addition to the New Dimension of User Friendliness}

The reason for adding user friendliness dimensions is because an application is considered to have good quality if the application is easy to use or easy to operate. User friendliness is intended in this case, namely, the application has features that are easily understood by users. So, to improve the quality of service an application product needs to be made an application that is easily understood, used and understood by users. To see a comparison between the base model and scenario 1 model can be seen in Fig. 5. The red color shows the base model and the blue color shows the scenario model 1 that has been made.

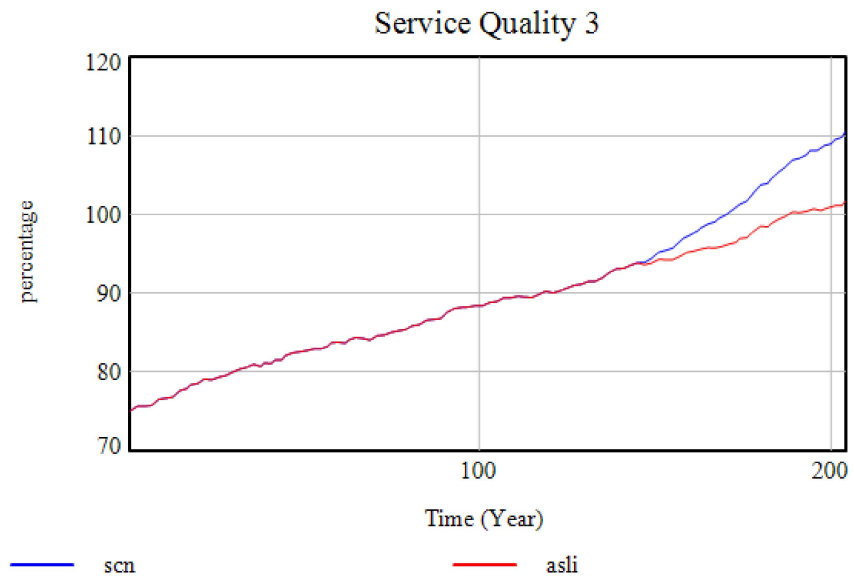

Fig. 5 Simulation results of scenario 1

\section{2) Scenario 2 Adding Infrastructure Dimensions}

The reason for the addition of the infrastructure dimension is that the addition of infrastructure based on the investment value of the company is expected to improve the quality of the application for the better. Infrastructure here can be in the form of additional bandwidth to speed up the response of the application when run. To see a comparison between the base model and scenario 1 model can be seen in Fig. 6 . The red color shows the base model and the blue color shows the scenario model 1 that has been made.

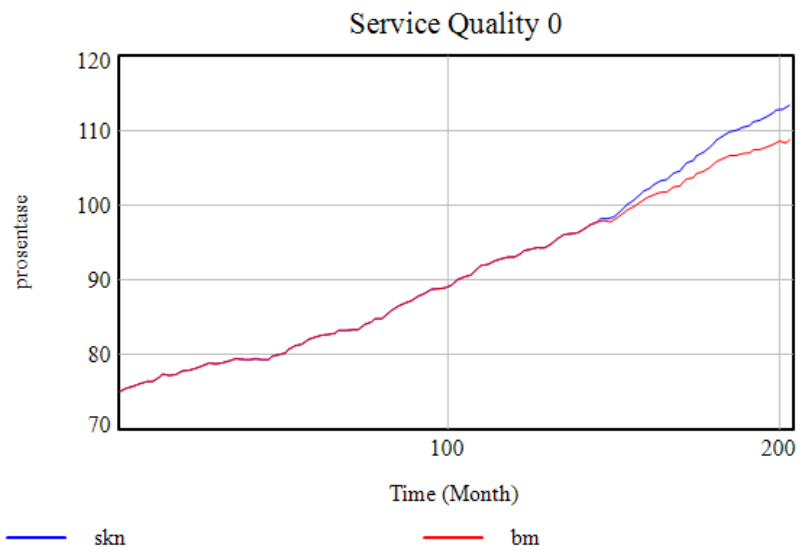

Fig. 6 Simulation results of scenario 2

\section{DISCUSSION}

The model simulation results obtained that improving service quality greatly affects customer satisfaction. Based on the initial simulation, it was found that the quality of service experienced ups and downs due to several factors not in accordance with the wishes of the customers. To maintain and improve customer satisfaction, the quality of T-Cash services must be improved. In improving service quality, this study uses 2 
scenarios to see which scenarios can be taken to increase customer satisfaction. Scenario 1 was created by adding a new dimension to user friendliness. Scenario 2 by adding an infrastructure dimension to improve the infrastructure of T-Cash so that it can be accessed more quickly. Based on these 2 scenarios, a policy can be taken that scenario 1 significantly increases customer satisfaction compared to scenario 2 .

To increase customer satisfaction can be done by providing electronic transaction services [20]. With the use of electronic transaction services, the frequency of transactions becomes faster and more efficient, so that each customer can save their time and costs. The company can also make customers more loyal by offering various financial services by renewing their electronic services. Electronic services that offer a variety of financial services will increase customer dependence on the services offered, so companies can generate higher income from each customer.

There are 5 dimensions which in this study are responsiveness, privacy, security, reliability, and efficiency. Where the simulation results show that the efficiency dimension has a strong influence on service quality. Quality and Matrix [21] considered if there are five dimensions that need to express the measurement of service quality, that is: tangible, reliability, assurance, responsiveness, and empathy. Service quality provides an incentive for customers to establish strong ties with the company. For the long term, service quality allows companies to understand carefully the expectations of customers and their needs, thus the company can increase customer satisfaction where the company maximizes pleasant customer experience and minimize unpleasant customer experiences [22]. Such things that exist in the five dimensions of service quality that are noticed by the company are the five dimensions that will determine the level of customer decisions. Service quality is a level of excellence that is expected to meet consumer desires. If the service received is as expected, the service quality is perceived as good and satisfying. If the service received exceeds consumer expectations, then the service quality is perceived as the ideal quality. Conversely, if the service received is lower than expected, then the service is perceived poorly [21]. According to Hemalatha et al [23], the existence of service quality will encourage customer decisions in using these services [23]. In addition, service quality can also encourage consumers to establish strong ties with the company.

\section{CONCLUSIONS}

After modeling the problems in improving the service quality of T-Cash, a number of important conclusions can be drawn regarding related policies. Based on the simulation that has been done, it can be concluded that the dimensions of responsiveness, privacy, reliability, security, and efficiency have many effects on improving service quality. By improving the quality of these dimensions, the service quality will increase every month. The simulation results are considered valid because they produce E1 values of 3\% (E1 valid when E1 $\leq 5 \%$ ) and E2 of $7 \%$ (E2 valid when E2 $\leq 30 \%$ ). Based on the scenario that has been done in scenario 1, it can be concluded that with the addition of the user friendliness dimension, the service quality will experience a significant increase over the next 5 years. In scenario 2, it can be concluded that with the addition of infrastructure dimensions, the service quality will experience a significant increase over the next 5 years compared to the initial model. The results of this study will be submitted to PT. Telkomsel as consideration to make policies for increasing customer satisfaction and loyality. In this study, the authors only using service quality to measure customer satisfaction. For further research, it is expected that the measurement of customer satisfaction can consider other factors such as costs, transactions and comparison of service quality to other competitors.

\section{REFERENCES}

[1] Khan, S. Mahapatra. "Service quality evaluation in internet banking: an empirical study in India," International Journal Indian Culture and Business Management, vol. 2, 2009.

[2] S. Behjati. "Interrelation between E-service Quality and E-satisfaction and Loyalty," European Journal of Business and Management, vol. 4, pp. 75-86, 2012.

[3] L. Zhao, Y. Lu, L. Zhang. "Assessing The Effects Of Service Quality And Justice On Customer Satisfaction And The Continuance Intention Of Mobile Value-Added Services : An Empirical Test Of A Multidimensional Model,” Decision Support Systems, vol. 52, pp. 645-656, 2012.

[4] P. Kotler,. Manajemen Pemasaran : Analisis, Perencanaan, Implementasi dan Pengendalian, Edisi Bahasa Indonesia Jilid 2, Jakarta, Salemba empat - Prentice Hall, hal 83-92. 2007.

[5] Y. Kuo, C. Wu, W. Deng. "The Relationships Among Service Quality, Perceived Value, Customer Satisfaction , And Post-Purchase Intention In Mobile Value-Added Services," Computers In Human Behavior, vol. 25, pp. 887-896, 2009.

[6] J. Chen, C. Zhang, Y. Xu. “The Role of Mutual Trust in Building Members Loyalty to a C2C Platform Provider,” International Journal of Electronic Commerce, vol. 14, pp. 147-71, 2009.

[7] D. Ball, P. Coelho, M. Vilares. "Service Personalization and Loyalty," Journal of Services Marketing, vol. 20, pp. 391 - 403. 2006.

[8] L. Marti. "Understanding Customer Loyalty Through System Dynamics The Case Of A Public Sports Service In Spain," Management Decision, vol. 47, pp. 151-172, 2009.

[9] E. Stiakakis, C. Georgiadis. "E-Service Quality : Comparing The Perceptions Of Providers And Customers," Managing Service Quality: An International Journal, vol. 19 Issue: 4, pp.410-430, 2009.

[10] Z. Yang, X. Fang. “Online Service Quality Dimensions And Their Relationships With Satisfaction: A Content Analysis Of Customer Reviews Of Securities Brokerage Services,” International Journal of Service Industry Management, vol. 15 (3), pp. 302-326, 2004. 
[11] F. Hamed, B. Saadan, B. Seman. "Determining the Influence of the Reliability of Service Quality on Customer Satisfaction The Case of Libyan ECommerce Customers," International Journal of Learning \& Development, vol. 5, 2015.

[12] A. Zeithaml, L. Berry, A. Parasuraman. "Behavioral Consequences of Service,” Journal of Marketing, vol. 60, pp. 31-46. 2013.

[13] G. Udo, K. Bagchi, P. Kirs. "E-Service Quality Perception , Satisfaction And Intention," International Journal of Information Management, vol. 30, pp. 481-492, 2010.

[14] Sterman, J.D. "Business Dynamics: Systems Thinking and Modeling for a Complex World,” Irwin McGraw-Hill, Boston. 2000.

[15] S. Kim, S. Wook “The Trade-Off Of Service Quality And Cost : A System Dynamics Approach,” Asian Journal on Quality, vol. 11, pp. $69-78,2010$.

[16] R. H. A Bourouni. “Customer Support Optimization Using System Dynamics : A Multi-Parameter Approach,” Kybernetes, vol. 45, pp. 900-914, 2016.

[17] Forrester, Jay W. "System Dynamics, Systems Thinking, and Soft OR," System Dynamics Review Summer, vol. 10, pp. 3. 1994.

[18] J. Burns. "Validation of Causal Loop Diagram", Rowls of Business Administration, Texas Tech University Lubbock, Texas 79409 2101. 2004.

[19] Y. Barlas. "Multiple tests for validation of system dynamics type of simulation models," European Journal of Operational Research 42, pp. 59-87 59. 1989.

[20] Y. Hu, P. Liao. "Finding Critical Criteria Of Evaluating Electronic Service Quality Of Internet Banking Using Fuzzy Multiple-Criteria Decision Making,” Applied Soft Computing Journal, vol. 11, pp. 3764-3770, 2011.

[21] S. Quality, P. Matrix. "Service Quality Evaluation By Service Quality Performance Matrix,” Total Quality Management, vol. 14, pp. 79-89, 2003

[22] Janita, Miranda. "Exploring Service Quality Dimensions in B2B Marketplaces," Journal of Electronic Commerce Research, vol. 14, pp. 363-386. 2013

[23] S. Hemalatha, L. Dumpala, B. Balakrishna. "The Asian Journal of Shipping and Logistics Service Quality Evaluation and Ranking of Container Terminal Operators through Hybrid Multi-Criteria Decision Making Methods," The Asian Journal of Shipping and Logistics, vol. 34, pp. 137-144, 2018. 